Retratos

AA 



\title{
A “CRiatura” E O "ESPElhO” o retrato de Machado de Assis por Marc Ferrez'
}

\author{
ThE “CREATURE” AND THE "MIRROR”: \\ THE PORTRAIT OF MACHADO DE ASSIS BY MARC FERREZ
}

\author{
Maria Inez Turazzi* \\ Universidade Federal Fluminense (UFF)
}

\begin{abstract}
RESU MO
Este artigo apresenta e discute um conjunto de informações, algumas das quais inéditas, sobre um retrato de Machado de Assis (1839-1908) atribuído ao fotógrafo Marc Ferrez (18431923). Analisando essa imagem, bem como seu contexto de produção e circulação (1880-1884), procuramos identificar e amplificar questões relevantes para o estudo das relações entre literatura e fotografia. Acredita-se que a história da fotografia em geral, e a história desse retrato em particular, quando articuladas ao cenário editorial brasileiro nos Oitocentos e à imensa fortuna crítica hoje existente sobre a vida e a obra de Machado de Assis, podem iluminar aspectos ainda obscuros da biografia do escritor e, ao mesmo tempo, lançar novas indagações e interpretações sobre sua imaginação criadora.

PALAVRAS-CHAVE

Fotografia, literatura, Machado de Assis, Marc Ferrez, retrato

Cada criatura humana traz duas almas consigo: uma que olha de dentro para fora, outra que olha de fora para dentro [...]. A alma exterior pode ser um espírito, um fluido, um homem, muitos homens, um objeto, uma operação.
\end{abstract}

Machado de Assis ${ }^{2}$

O que parecia ser uma imprecisão na autoria de um retrato de Machado de Assis, publicado junto com sua biografia, em agosto de 1884, acabou não escapando ao comentário crítico da sessão "Livros a Ler", na Revista Illustrada:

\footnotetext{
*mi.turazzi@gmail.com, inezturazzi@pesquisador.cnpq.br

${ }^{1}$ Agradecimentos: A Alexei Bueno, Anselmo Maciel e Maria do Socorro (Academia Brasileira de Letras); Francisca Helena M. Araújo e Monica Carneiro Alves (Fundação Biblioteca Nacional); Joanna Balabram (Instituto Moreira Salles); Manoel Portinari Leão e George Ermakoff (colecionadores).

${ }^{2}$ Por opção da autora, nas citações de Machado de Assis e Arthur Barreiros a grafia foi atualizada segundo o Novo Acordo Ortográfico (N. R.).
} 
Temos à vista o primeiro número da Galeria Contemporânea do Brasil, publicação quinzenal, política, literária, artística, agrícola e industrial dos Srs. Lombaerts \& C., [e do] fotógrafo o Sr. Marc Ferrez.

Estreia com o Sr. Machado de Assis, de quem nos dá o retrato, um fac-símile e a biografia. $[\ldots]$

O retrato é difícil dizer por quem foi feito.

Na capa se diz: Marc Ferrez, fotógrafo; dentro, porém, no baixo do retrato, está escrito, d'um lado: "Fotografia inalterável, Marc Ferrez"; do outro: "Cliché, Insley Pacheco."

Ora, em primeiro lugar, a fotografia não é tal inalterável; em segundo, como é que sendo o cliché do Sr. Insley Pacheco, o fotógrafo é o Sr. Ferrez?

A empresa que resolva o caso. ${ }^{3}$

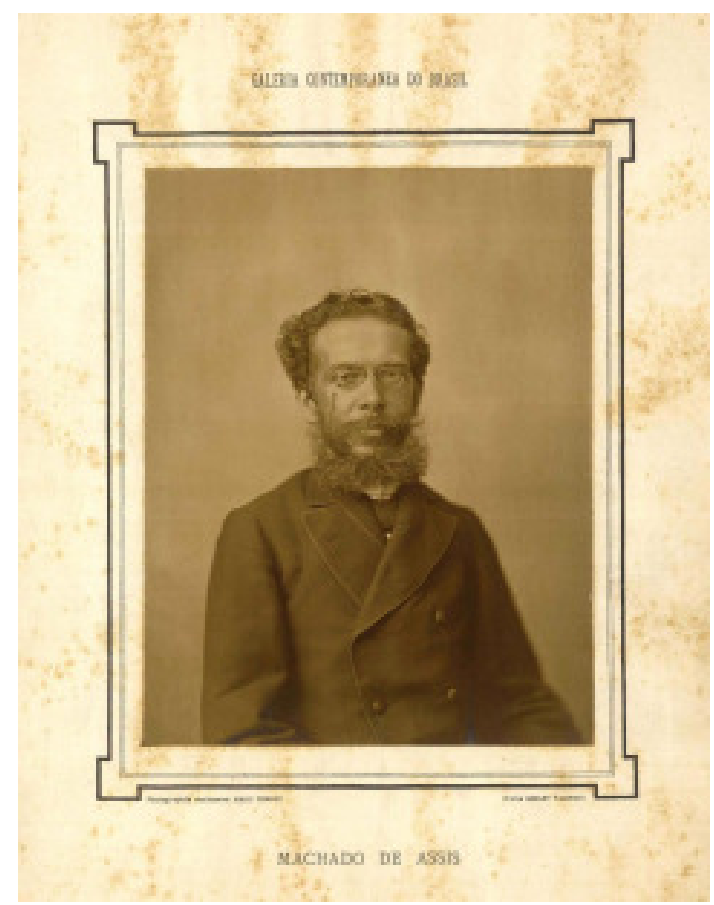

FIGURA 1 - Retrato de Machado de Assis, Galeria Contemporânea do Brasil, 1884

Impressão em platinotipia por Marc Ferrez, a partir do negativo de vidro de Joaquim Insley Pacheco.

Fonte: Acervo Fundação Biblioteca Nacional.

O retrato, seja na longa tradição literária e artística, como em sua expressão fotográfica mais "recente", depois do aparecimento da daguerreotipia em 1839, tem sido definido como a "arte de fixar um personagem". 4 A representação da imagem de uma pessoa, a reconstituição de seus traços fisionômicos, certo gênero de obra de arte, a descrição ou o modelo de alguém, são antigas acepções da palavra (do italiano rittrato) que, no decorrer dos Oitocentos, assistiram à difusão de um novo significado: o retrato como sinônimo de imagem fotográfica. A fotografia conferiu imensa popularidade à representação do indivíduo, reforçando a antiga associação entre fisionomia e identidade, traduzida pela expressão do rosto:

\footnotetext{
${ }^{3}$ ASSIS. Livros a Ler, p. 6, grifos do original. Revista publicada por Angelo Agostini (1843-1910).

${ }^{4}$ CIORAN. Antologia do retrato: de Saint-Simon a Tocqueville, p. 13.
} 
Esta é a parte do corpo a que se chama, com justa razão, espelho da alma, é o seu quadro resumido, em que todas as suas cores verdadeiras e todos os seus traços evidentes são representados e onde os vícios e as virtudes que dominam a alma, ou que ela possui, são lidos claramente. ${ }^{5}$

Mas, se o rosto é atributo essencial do retrato e "espelho da alma", o rosto fotografado logo se transformaria em "espelho com memória". Por isto mesmo, o retrato por meios fotográficos tornou-se também a maior vítima da persistente crença em sua "ilusão mimética", ainda que a fotografia tenha concedido aos indivíduos singularidade e consciência social de si mesmos. Annateresa Fabris ofereceu-nos, com seu amplo e acurado estudo sobre o "processo de ficcionalização que a fotografia impôs ao retrato desde o seu surgimento", ${ }^{6}$ as ferramentas conceituais e metodológicas para uma análise do retrato fotográfico como "identidade virtual", isto é, como uma "abstração" ou "construção artificial" em torno da qual se estabelece uma representação do indivíduo e sua interação com o mundo. A distinção entre o "homem exterior" e o "homem interior", referida por Emil Cioran (1911-1995) ao apresentar os retratos traçados pela pena de célebres escritores, ${ }^{7}$ por sua vez, articula de forma sintética as relações sempre complexas que cada um traz do mundo e de si mesmo, relações dadas a ver pela arte do retrato. É esse o recorte temático pretendido aqui, diante das inúmeras possibilidades de estudo das conexões entre literatura e fotografia que se apresentam (fotografia como ilustração do texto literário ou poético; procedimentos fotográficos na literatura; a metáfora fotográfica na literatura; autorretrato, autobiografia; literatura, fotografia e memória; os escritores, editores e a fotografia; o imaginário da fotografia na literatura; fotografia e testemunho; literatura, fotografia e representação).

O que pode então oferecer como contribuição para esses estudos o retrato fotográfico de um personagem já "fixado" por tantos outros retratos, textuais e visuais? As publicações e exposições sobre Machado têm difundido uma ampla iconografia do escritor em seu tempo, destacando-se, naturalmente, os seus próprios retratos, quase todos já bastante conhecidos, embora algumas novidades possam, vez por outra, aparecer. ${ }^{8}$ A fotografia, sua cultura e seu vocabulário estão presentes em sua vida e em sua obra em diversas passagens. ${ }^{9}$ Mas o que essa presença revela sobre o seu mundo, sua personalidade, sua imaginação? Apesar da imensa fortuna crítica sobre a obra

\footnotetext{
${ }^{5}$ TAXIL. L'astrologie et la physiognomonie en leur splendeur apud COURTINE; CLAUDINE. História do rosto, p. 45.

${ }^{6}$ FABRIS. Identidades virtuais: uma leitura do retrato fotográfico, p. 17-18.

${ }^{7}$ CIORAN. Antologia do retrato: de Saint-Simon a Tocqueville, p. 13.

${ }^{8}$ Uma apreciação criteriosa da fisionomia e da idade de Machado, segundo seus retratos, pode ser vista em MACHADO. Dicionário de Machado de Assis, p. 291-295. A obra de Guimarães e Sacchetta, A olhos vistos: uma iconografia de Machado de Assis, lançada no centenário da morte do escritor, reúne mais de duzentas imagens, compreendendo retratos, caricaturas, desenhos, alegorias, documentos pessoais, manuscritos, autógrafos, cartões-postais, cartões de visita, capas e folhas de rosto de suas principais obras. É a mais abrangente coletânea visual sobre Machado de Assis e seu tempo, onde se incluem 24 fotografias do escritor (algumas estão com erro de datação).

${ }^{9} \mathrm{O}$ que pode ser facilmente realizado utilizando-se os recursos de busca e indexação por meios digitais nos textos do escritor, disponíveis em diversos sites.
} 
machadiana, ainda são pouco conhecidas as relações do escritor com a fotografia, destacando-se nesse panorama sem grande densidade o instigante ensaio de Thomas Sträter sobre o "olhar fotográfico de Machado de Assis". ${ }^{10}$ Detendo-se no enigma lançado por Alfredo Bosi em torno de um olhar que é "ora cognitivo e, no limite, definidor, ora é emotivo e passional", ${ }^{11}$ Sträter sugere-nos que Machado teria um "olhar fotográfico":

Adotando a postura de um fotógrafo com o intento de retratar uma pessoa ou um grupo de pessoas dentro de um certo ambiente determinante, Machado lança o olhar ao objeto de interesse, escolhe o modelo, reflete sobre o cadrage idôneo e necessário, arranja a iluminação, focaliza os detalhes e por fim projeta as imagens na tela da imaginação do leitor, e tudo isso por meio da linguagem. ${ }^{12}$

As múltiplas conexões entre Machado e a fotografia, em diversas fases da vida privada e da imagem pública do escritor, assim como de sua vasta obra continuam sendo um enigma. As repercussões da imagem do "homem exterior", que os retratos fotográficos ajudaram a singularizar, sobre o "homem interior", apontam caminhos. O cruzamento desses retratos com sua correspondência ativa e passiva, seus poemas, suas crônicas, as primeiras edições de obras literárias, as biografias e os jornais de época, os documentos de carreira como funcionário público, entre outras formas de intertextualidade para a análise das imagens fotográficas, oferece um itinerário de pesquisa fecundo. Esse cruzamento, que naturalmente não se esgota neste artigo e menos ainda nos retratos aqui comentados, também nos sugere certas conexões entre figuras-chave do Brasil oitocentista, estabelecidas a partir da fotografia e suas práticas. Afinal, o que Machado, o "mestre do retrato psicológico", o "viajante imóvel”, o "oficial de gabinete", teria dialogado com Joaquim Insley Pacheco (c. 1830-1912), o "fotógrafo da Casa Imperial”, em seus encontros para uma sessão de pose? O que Marc Ferrez (1843-1923), o "mestre da fotografia de paisagem", o "fotógrafo andarilho" e o "empresário da imagem", tão ocupado com a documentação de obras públicas, teria compartilhado com o funcionário da Secretaria de Agricultura, Comércio e Obras Públicas do Império? Além da especulação, de teor mais imaginativo do que acadêmico, podemos (e devemos) perguntar-nos: como as trajetórias e as obras desses artistas da imagem e homens de letra dialogaram entre si? Ou ainda, como se articulavam a cultura letrada e a cultura visual no Brasil oitocentista? Qual a intervenção da fotografia nesse intercâmbio de sensibilidades, linguagens e projetos?

Machado foi o primeiro a fazer na imprensa carioca um resumo histórico da chegada da daguerreotipia ao Brasil, invenção anunciada e oferecida ao mundo pela França, em agosto de 1839, ano do nascimento do escritor. ${ }^{13}$ Para Sträter, ele não desconhecia essa coincidência de datas quando tratou do tema, notando-se em sua obra "um distanciamento da idéia ingênua de que fotografar signifique apenas reproduzir o real, sendo antes construir um discurso, como pintar e escrever". ${ }^{14}$ A novidade desembarcou

\footnotetext{
${ }^{10}$ STRÄTER. De retratos, espelhos e reproduções: o olhar fotográfico de Machado de Assis, p. 91-128.

${ }^{11}$ BOSI. Machado de Assis: o enigma do olhar, p. 10.

${ }^{12}$ STRÄTER. De retratos, espelhos e reproduções: o olhar fotográfico de Machado de Assis, p. 119.

${ }^{13}$ Sobre a história da expedição, ver TURAZZI. A máquina viajante, p. 18-25.

${ }^{14}$ STRÄTER. De retratos, espelhos e reproduções: o olhar fotográfico de Machado de Assis, p. 97.
} 
na capital do Império em poucos meses, trazida por um navio-escola em "viagem de instrução" ao redor do mundo, a primeira do gênero com esse tipo de equipamento. A experiência com a daguerreotipia, noticiada pelo Jornal do Commercio, em 17 de janeiro de 1840, foi comentada por Machado, anos mais tarde, no Diário do Rio de Janeiro:

Há vinte e quatro anos, em janeiro de 1840, chegou ao nosso porto uma corveta francesa, L'Orientale, trazendo a bordo um padre de nome Combes [sic]. Este padre trazia consigo uma máquina fotográfica. Era a primeira que aparecia em nossa terra. O padre foi à hospedaria Pharoux, e dali, na manhã do dia 16 de janeiro, reproduziu três vistas - o largo do Paço, a praça do mercado e o mosteiro de São Bento. Três dias depois, tendo Sua Majestade aceitado o convite de assistir às experiências do milagroso aparelho, o padre Combes [sic], acompanhado do comandante da corveta, foi a S. Cristóvão, e ali fez-se nova experiência; em 9 minutos foi reproduzida a fachada do Paço, tomada de uma das janelas do torreão $[\ldots] \cdot{ }^{15}$

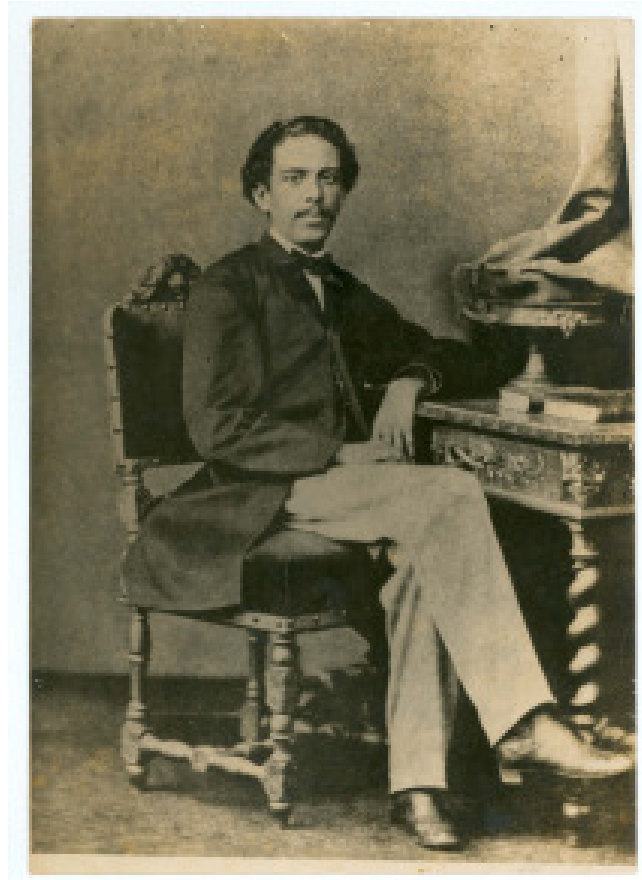

FIGURA 2 - Joaquim Insley Pacheco. Retrato de Machado de Assis, c. 1864

Formato carte de visite, c. 6,0 x 9,5 cm (reprodução).

Fonte: Acervo Academia Brasileira de Letras.

A crônica de Machado, escrita em 1864, coincide com a época (como podemos estabelecer pelo confronto com seus retratos) na qual ele frequentou o estabelecimento de Pacheco, já então um dos mais afamados retratistas do Rio de Janeiro. ${ }^{16}$ A experiência pessoal no salão de pose parece, assim, ter contribuído para seu interesse pela experimentação fotográfica pioneira, marcante também na vida da cidade. Um dos

\footnotetext{
${ }^{15}$ ASSIS. Ao acaso, p. 1. Sobre a identidade do daguerreotipista, cujo nome correto é Louis Comte, ver TURAZZI. A máquina viajante, especialmente p. 24.

${ }^{16}$ ERMAKOFF. Rio de Janeiro, 1840-1900: uma crônica fotográfica, p. 227-228. Sobre o fotógrafo, ver também < http://enciclopedia.itaucultural.org.br/pessoa21635/Insley-Pacheco $>$.
} 
retratos realizados no estúdio de Pacheco é bastante conhecido (FIG. 2), pois já foi amplamente reproduzido em biografias, edições literárias, livros didáticos e exposições. Retrato que exemplifica, com perfeição, a lógica do ritual de pose no mundo oitocentista:

No atelier do fotógrafo, o modelo posa apenas meio minuto diante do instrumento. É preciso que antes de entrar no salão de pose, ele tenha esquecido na sala de espera qualquer preocupação exterior: que ali, folheando os álbuns, examinando os retratos expostos, indagando sobre o seu valor artístico e o caráter de cada um deles, possa apreciar e captar a pose e a expressão que melhor lhe convenha e que alguns conselhos do artista lhe ajudarão a assumir. Tudo deve ser feito para distrair o visitante e dar ao seu semblante uma expressão de calma e felicidade, para fazer nascer em seu espírito ideias agradáveis, risonhas que, clareando os seus traços com um doce sorriso, façam desaparecer aquela expressão séria que a grande maioria tem tendência a assumir, e que, sendo a que mais se exagera, dá geralmente à fisionomia um ar de sofrimento, de contração ou de tédio. ${ }^{17}$

O resultado dessa encenação diante da câmara é a imagem de um jovem que, como tantos outros de sua época, representa um tipo social. Com 25 anos, Machado é o jornalista, poeta, tradutor e dramaturgo que ainda não se notabilizara como romancista. Trata-se, portanto, de um gênero de retrato no qual se constrói "uma identidade padronizada que desafia, não raro, o conceito de individualidade, permitindo forjar as mais variadas tipologias". ${ }^{18}$ O outro retrato (FIG. 3), obtido na mesma sessão de pose, só mais recentemente veio a ser publicado e exposto, na Academia Brasileira de Letras, durante as comemorações pelo centenário de falecimento do escritor (2008). Embora orientado para a mesma encenação fotográfica, ele acrescenta à imagem um artefato que, embora comum nos retratos da época, teria para Machado o peso de um destino: o livro e, com ele, o leitor.

\footnotetext{
17 “Chez le photographe, le modèle pose à peine une demi-minute devant l'instrument. Il faut qu'avant d'entrer dans le salon de pose, il ait oublié dans le salon d'attente toute préoccupation extérieure: qu'en y feuilletant les albums, en examinant les portraits exposés, en interrogeant sur la valeur artistique, sur le caractère propre à chacun d'eux, il ait pu apprécier et saisir les poses et l'expression qui lui convienne le mieux, et que quelques conseils de l'artiste suffisent ensuite pour lui faire prendre. Tout doit être mis en oeuvre pour distraire le visiteur et donner à son visage une expression de calme et de bonheur, pour faire naître dans son âme des idées agréables, riantes qui, éclairant ses traits d'un doux sourire, en fassent disparaitre cette expression sérieuse que le plus grand nombre a une tendance à prendre, et qui, étant celle qui s'exagère le plus, donne ordinairement à sa physionomie un air de souffrance, de contraction ou d'ennui." KEN. Dissertations historiques, artistiques et scientifiques sur la photographie, p. 207-208, tradução nossa.

${ }^{18}$ FABRIS. Identidades virtuais: uma leitura do retrato fotográfico, p. 15.
} 


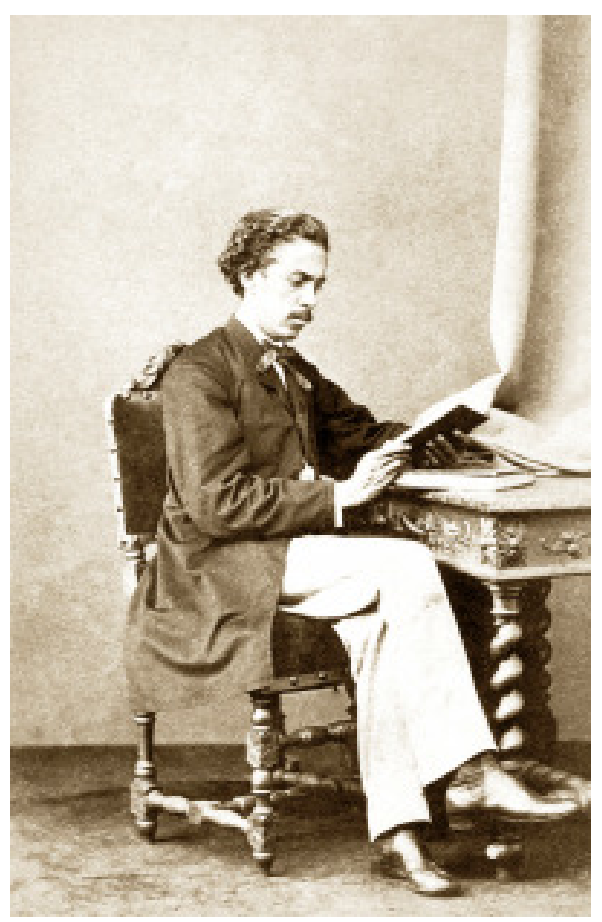

FIGURA 3 - Joaquim Insley Pacheco. Retrato de Machado de Assis, c. 1864

Formato carte de visite, c. $6,0 \times 9,5 \mathrm{~cm}$.

Fonte: Coleção Manoel Portinari Leão.

Retratos fotográficos do escritor, a princípio transpostos para a litogravura, estamparam a edição de periódicos ilustrados desde a década de 1870, até que a veiculação pública de sua fisionomia fosse consideravelmente ampliada, já no final do século, pela impressão gráfica de fotografias. ${ }^{19}$ Voltando então à imagem de Machado que serviu de ilustração para a Galeria Contemporânea do Brasil, trata-se de um retrato obtido também por Pacheco, autor do cliché (negativo), posteriormente impresso em platinotipia por Ferrez, responsável pela introdução no Brasil de diversas inovações no mundo das imagens. O emprego de papéis de platina no processamento fotográfico foi uma dessas inovações, apresentada por Ferrez na exposição geral da Academia Imperial de Belas Artes de 1884. As fotografias em platinotipia eram consideradas "inalteráveis", por sua estabilidade e permanência, além de oferecerem grande variedade tonal e riqueza de detalhes. O exemplar com o retrato de Machado disponível na Biblioteca Nacional, uma raridade de valor excepcional, já foi reproduzido no século passado por meios fotomecânicos, mas a qualidade dessa reprodução não ofereceu aos estudos machadianos uma fonte muito inspiradora. ${ }^{20} \mathrm{O}$ retrato pouco frequentou a bibliografia dedicada ao escritor e, provavelmente, não teria sido escolhido, como em 2011, para figurar na

\footnotetext{
${ }^{19} \mathrm{O}$ Archivo Contemporâneo, de 30 de janeiro de 1873, traz na capa um retrato de Machado (ao lado de José de Alencar), obtido a partir de fotografia de Insley Pacheco. Ver MACHADO. Dicionário de Machado de Assis, p. 292.

${ }^{20}$ Ver GRANDES PERSONAGENS, v. 6, p. 33. O artigo sobre Machado, escrito por Julia Maria Leonor Scarano, é profusamente ilustrado. Constitui, portanto, apenas um exemplo, entre muitos, da circulação do referido retrato.
} 
abertura do site criado pela Academia Brasileira de Letras em sua homenagem. ${ }^{21}$ A imagem que hoje circula na internet é, no entanto, uma reprodução digital por contato, realizada diretamente do negativo que deu origem à impressão em platinotipia apresentada na Galeria. 22

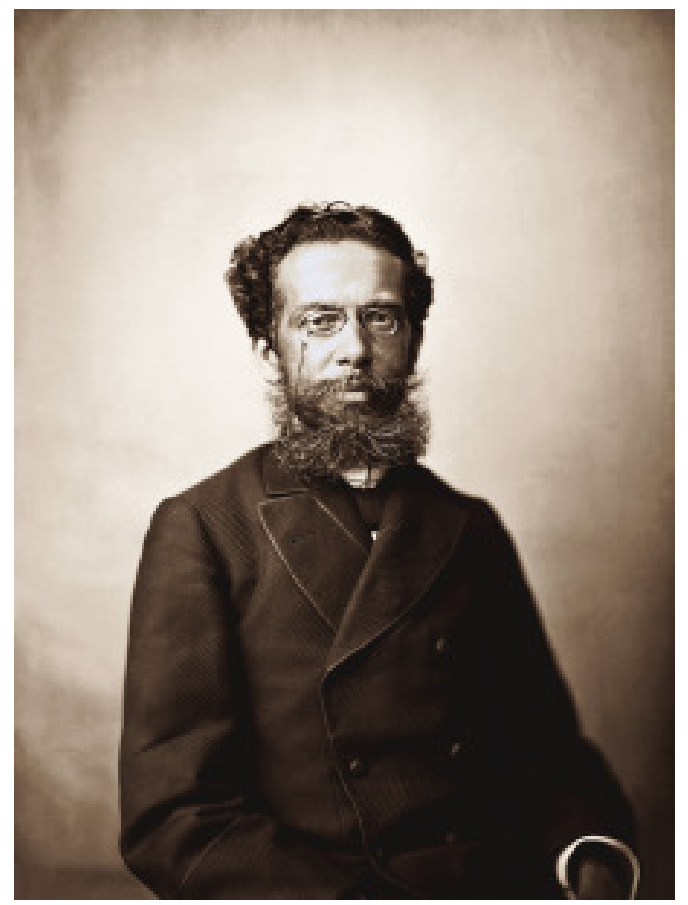

FIGURA 4 - Joaquim Insley Pacheco (atribuído a Marc Ferrez). Retrato de Machado de Assis, c. 1880

Negativo original em vidro (digitalizado), c. 24,0 x 18,0 cm.

Fonte: Marc Ferrez - Coleção Gilberto Ferrez - Acervo Instituto Moreira Salles.

Na última década, o acervo de negativos de vidro da Casa Marc Ferrez, adquirido com a compra da Coleção Gilberto Ferrez pelo Instituto Moreira Salles, em 1999, tem sido reproduzido por meios digitais e por impressões contemporâneas com grande apuro técnico. Em 2005, a imagem de Machado integrou o catálogo da exposição O Brasil de Marc Ferrez e, em 2007, figurou na capa dos Cadernos de Literatura Brasileira, sendo ambos publicados por iniciativa do instituto. Consagrou-se, então, em escala muito mais ampla, uma autoria e uma data equivocadas ("Marc Ferrez, cerca de 1890") para aquele que acreditamos ser o mais expressivo retrato de Machado de Assis. A existência desse negativo de vidro, em meio aos 103 retratos da Casa Marc Ferrez, em um acervo que totaliza 3.954 negativos de vidro (segundo o banco de dados do instituto), serviu como indicação aparentemente segura para sua autoria ser atribuída a Ferrez. Equívocos semelhantes são comuns na catalogação de acervos fotográficos e, por si só, não justificariam este artigo, não fosse esse retrato tão importante para os cruzamentos aqui

\footnotetext{
${ }^{21}$ Ver $<$ http://www.machadodeassis.org.br $>$.

${ }^{22}$ Os dois foram parceiros em outras empreitadas: em 1878, Ferrez levou para Paris e apresentou à apreciação dos membros da Societé Française de Photographie, em nome de Pacheco, seus portraits-promenade (retratos fotográficos com paisagens pintadas ao fundo). TURAZZI. A vontade panorâmica, p. 41.
} 
propostos. Em todo caso, vale ressaltar que a autoria (coletiva) no mundo das imagens sempre esteve condicionada por hierarquias e valorações que cada época atribui aos processos de criação e circulação dessas obras.

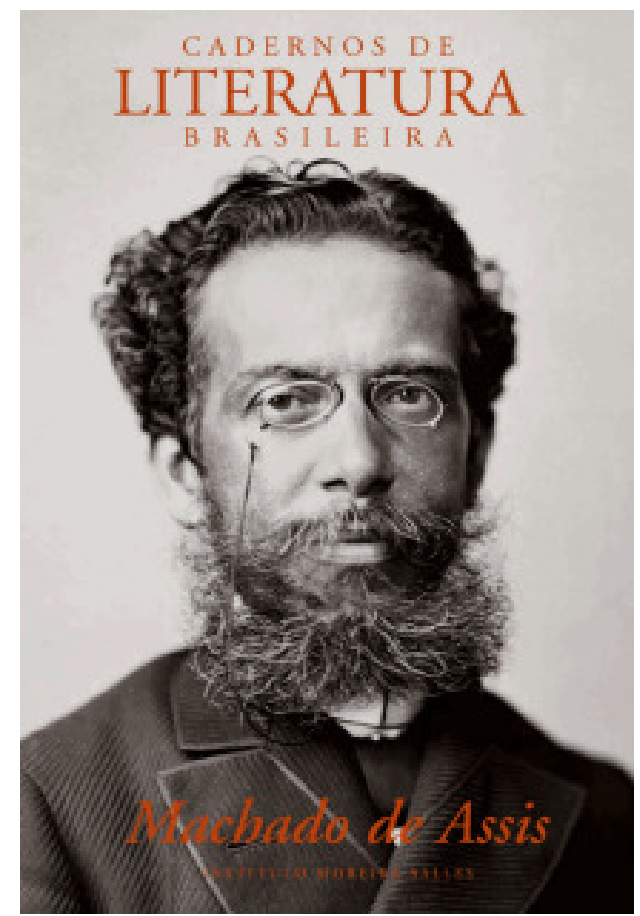

FIGURA 5 - Capa de Cadernos de Literatura Brasileira: Machado de Assis

Fonte: IMS. Cadernos de Literatura Brasileira: Machado de Assis.

Observando-se outros retratos do escritor, seus traços fisionômicos também indicam uma data anterior a 1890 para a obtenção do retrato por Pacheco (na verdade, cerca de 1880). Um aspecto desimportante? De modo algum, como veremos em seguida. A época coincide com o lançamento de várias publicações pelo editor belga Henri Gustave Lombaerts (1845-1897), filho do renomado encadernador Jean Baptiste Lombaerts (18211875), tendo ambos chegado ao Rio de Janeiro, vindos de Antuérpia, ainda na década de 1840. Como impressor litógrafo, H. G. Lombaerts aventurou-se desde cedo no lançamento de jornais e fascículos ilustrados por litogravuras, platinotipias e fototipias, quando estas ainda davam os seus primeiros passos por aqui. Em 1879, lançou A Estação ("jornal ilustrado para a família") e, no ano seguinte, A Nova Semana Illustrada e Pena e Lapis.

Orlando da Costa Ferreira, em seu abrangente levantamento sobre o mundo editorial da época, fez um breve comentário sobre o retrato de Machado publicado na Galeria, cuja impressão teria contado com a "assistência de Ferrez". ${ }^{23} \mathrm{O}$ fotógrafo esteve, na verdade, associado a Lombaerts em diversos projetos, chegando ambos a formar uma sociedade comercial para o lançamento de platinotipias na Galeria e, mais tarde, para a impressão de fototipias no jornal A Estação, assim como para a edição de postais e

\footnotetext{
${ }^{23}$ FERREIRA. Imagem e letra: introdução à bibliologia brasileira, p. 234.
} 
outras publicações ilustradas ao longo das décadas de 1880 e $1890 .{ }^{24}$ Ambos também estiveram próximos de Machado em muitas ocasiões. Em 1880, especificamente, Ferrez realizou fotografias da Exposição Camoniana apresentada na Biblioteca Pública (hoje Biblioteca Nacional), comemoração que contou com o engajamento de Machado. O ano coincide com o tricentenário de Camões e com a apresentação, no teatro de D. Pedro II, da comédia machadiana Tu, só tu, puro amor... Lombaerts publicou a peça em 1881 e, no ano seguinte, reuniu os contos do escritor em Papéis avulsos. Quando escolheu Machado para uma das personalidades que comporiam sua Galeria, sabia o que estava oferecendo ao público:

A Galeria Contemporânea do Brasil destina-se a publicar, mensalmente, os retratos dos homens notáveis do país, tanto nacionais como estrangeiros, que se tenham distinguido nas ciências, nas letras, nas artes, na indústria, no comercio, na política, na agricultura e em todos os ramos da atividade humana. A execução dos retratos está a cargo da perícia do nosso amigo o Sr. Marc Ferrez, introdutor entre nós do sistema de platinotipia, que se recomenda pela inalterabilidade e beleza de detalhes. Cada fascículo da nossa publicação, que se vende separadamente, contém além do retrato uma breve notícia biográfica e um autógrafo do escritor ou político ou a reprodução de alguma obra quando se trata de algum artista. Os editores da Galeria Contemporânea do Brasil não estabelecem preferência de natureza alguma, nem se filiam aquela ou a esta crença; irão publicando os retratos à proporção que lhes enviar o fotógrafo. A redação está confiada a escritores hábeis e neutros que saberão fazer a devida justiça aos méritos de cada um. ${ }^{25}$

Um retrato do escritor, assinado pela Lithographia de P. Braga, sendo a estampa, como era praxe na época, uma transposição para a pedra litográfica de outra fotografia tirada por Pacheco, já havia saído na capa do segundo número do jornal Pena e Lapis, de 10 de junho de 1880. Fundado por Arthur Barreiros (1856-1885), o jornal pode ter encomendado o retrato ou, simplesmente, aproveitado a sua existência para inserir a imagem na biografia do escritor. A primeira do gênero que lhe era oferecida e que apontava, em tom irônico, o fato de Machado não pertencer aos quadros do Instituto Histórico e Geográfico Brasileiro. Barreiros traduziu peças para o teatro, publicou o romance Beleza invisível (1881) e foi responsável pela criação de diversos periódicos de vida tão efêmera como quase todos os seus congêneres. ${ }^{26}$ O jornalista era amigo de Machado e foi também quem escreveu essa biografia, reproduzida poucas semanas depois no jornal A Estação e, quatro anos mais tarde, na Galeria Contemporânea do Brasil, onde o texto apareceu ampliado e acompanhado pelo retrato em platinotipia. Uma biografia, portanto, que já nasceu ilustrada e foi, certamente, um marco na vida pública de Machado, fato que não pode ser desconsiderado na imagem do "homem exterior" sobre "homem interior".

${ }^{24}$ TURAZZI. Cronologia, p. 305-314. O nome de Ferrez ("Editores proprietários: Lombaerts, Marc Ferrez \& C.”) aparece na primeira página d'A Estação, entre 15 de maio de 1891 (n. 9) e 30 de setembro do mesmo ano (n. 18).

${ }^{25}$ Galeria Contemporânea do Brasil, ago. 1884. A publicação, sob o código "FOTOS ARM 6.7.2 (14-15)", foi digitalizada pela Fundação Biblioteca Nacional para a elaboração deste artigo e passará a integrar a Hemeroteca Digital (<http://hemerotecadigital.bn.br $>$ ).

${ }^{26}$ Sobre o jornalista, ver $<$ http://www.ecodosul.furg.br $>$. 
O primeiro número da Galeria, coleção de "notabilidades" tão ao gosto da época, foi dedicado ao astrônomo de origem belga Luís Cruls (1848-1908), então diretor do Observatório Imperial (diferentemente do que informou a seção "Livros a Ler" da Revista Illustrada, citada na abertura deste artigo). O seu retrato tem fatura idêntica ao de Machado e ambos vestem, inclusive, o mesmo modelo de fardão. ${ }^{27} \mathrm{O}$ título, a apresentação, o conteúdo e o formato da Galeria indicam, assim, que sua publicação atendeu a um programa editorial muito claro, tendo a ciência como norte e o progresso como horizonte:

Os editores da Estação encetaram a 1음 do corrente a publicação da Galeria Contemporânea do Brasil, que tem no seu próprio título um programa definido e o que é mais - um programa permanente. Devem figurar nesta Galeria, cujo êxito nos parece incontestável, todas as notabilidades do Brasil, tanto nacionais como estrangeiras, que hajam concorrido para o progresso do nosso país. O primeiro número, além de uma bela fotografia em ponto grande, tirada pelo senhor Marc Ferrez, contém um autógrafo e o perfil biográfico do Dr. L. Cruls, diretor do Observatório Astronômico do Rio de Janeiro [...]. O segundo número, que está no prelo e deve ser posto à venda no fim do corrente mês, trará o retrato, um autógrafo e a biografia do ilustre colaborador desta folha, Sr. Machado de Assis. ${ }^{28}$

O perfil biográfico e o autógrafo de Machado, dispostos em conjunto com sua fisionomia retratada por "bela fotografia em ponto grande", compunham uma persona para consumo público. Escrito por quem lhe era tão próximo, esse retrato textual e visual, assemelha-se também àquele que veio à tona, recentemente, com a publicação de toda a correspondência ativa e passiva do escritor, desfazendo assim o estereótipo de um sujeito desde sempre casmurro e antissocial. ${ }^{29}$ Pelo menos nessa época, era outra a imagem de Machado de Assis:

Ele é simplesmente um vivo e alegre camarada, que se faz rapaz com os rapazes, que não nos dá o louvor a juros ou com a intenção de agremiar a caudatários, mas que nos adverte e estimula, nobremente e sem ódios. [...] No trato íntimo, benévolo, discreto, polido, admirador e seguidor das práticas britânicas, gentleman, em uma palavra; na palestra é ainda um escritor de raça, deleitável, copioso em ditos, penetrante, arguto, com um reparo para cada fato, com um remoque para toda dissonância. ${ }^{30}$

O retrato de Machado na Galeria, inserido em um projeto civilizatório para o Brasil, compõe uma "biografia dramatizada" do escritor, no sentido que lhe atribui Baudelaire de ser uma imagem capaz de enfeixar "o drama natural inerente a todo homem". ${ }^{31}$ A expressão da face, o olhar frontal, a posição dos lábios, o caimento dos ombros, a irregularidade da barba, o desalinho dos cabelos, a nitidez da pele (um capítulo à parte em toda a escrita biográfica sobre Machado ${ }^{32}$ ), tudo nesse retrato confere

\footnotetext{
${ }^{27}$ Para uma apreciação conjunta dos dois retratos, ver O Brasil de Marc Ferrez, p. 222-223.

${ }^{28}$ A Estação, 15 jul. 1884, p. 11.

${ }^{29}$ Edição coordenada por Sergio Rouanet e publicada pela Academia Brasileira de Letras.

${ }^{30}$ BARREIROS. Biografia de Machado de Assis apud PIZA. Machado de Assis, um gênio brasileiro, p. 237-238.

${ }^{31}$ BAUDELAIRE. Salon de 1859 apud FABRIS. Identidades virtuais: uma leitura do retrato fotográfico, p. 21.

${ }^{32}$ Ver, por exemplo, o texto de Marcelo Coelho, na seção "Confluências", sobre esse retrato e a questão racial, em Cadernos de Literatura Brasileira: Machado de Assis.
} 
singularidade à sua fisionomia, em clara intimidade com a câmara, a despeito dos elementos comuns aos demais retratos da época, como o sobretudo e o pince-nez. Marcel Proust, por exemplo, trazia sua figura sempre vestida com um sobretudo "à moda do século XIX", mesmo quando a virada do século já havia ditado outra moda. Nos retratos do escritor francês, o olhar e a pose, não sua indumentária, é que fixavam para a posteridade o universo proustiano. Para José Castelo, aquele sobretudo clássico era uma espécie de "casulo", ou de "escudo protetor", empregado por Proust "para se contrapor aos golpes do real". ${ }^{33}$ Além de conviver com renomados fotógrafos parisienses, Proust foi profundamente marcado pela presença da fotografia, recorrendo com frequência a um vocabulário fotográfico para exprimir ideias e emoções. Ele próprio comparou sua obra com um "instrumento ótico" que permitia ao leitor enxergar melhor a si mesmo:

O leitor precisa ler de certa forma para ler bem: o autor não deve se ofender com isso, mas, ao contrário, conceder a maior liberdade ao leitor dizendo-lhe: 'Veja você mesmo se enxerga melhor com esta lente aqui, com aquela ou com aquela outra'. ${ }^{34}$

As artes do retrato na fixação de um personagem e seu poder de sedução e encantamento eram bem conhecidos do jornalista e funcionário público, tanto quanto do escritor Machado de Assis. Um "retrato", com críticas sutis ao imperador Pedro I, cuja estátua tinha sido inaugurada no Largo do Rocio, custara a Machado o seu afastamento dos "Comentários da Semana" nas páginas do Diário do Rio de Janeiro. ${ }^{35}$ Para alguém que integrara, em 1872, uma comissão ministerial (a do Dicionário marítimo brasileiro) e, no ano seguinte, fora nomeado primeiro oficial da Secretaria de Agricultura, Comércio e Obras Públicas, chegando a oficial-de-gabinete, em 1880, antes de se aposentar como diretor, esse gênero de homenagem também era visto como uma moeda de troca para a obtenção de favores. Em 1884, ao assinar a seção "Balas de Estalo", na Gazeta de Notícias, Machado espetou o tema:

Você não tem lido nos jornais notícias de comissões que vão oferecer isto ou aquilo, um retrato, uma venera, etc., a pessoas completamente obscuras ou insignificantes?

- Tenho; leio muitas vezes.

Pois saiba que não há tal. São casos de comissiomania. Essas pessoas vêem, sinceramente, por alucinação, uma comissão diante de si, oferecendo-lhes alguma coisa - venera ou retrato, ouvem os discursos, agradecem, convidam para um copo d'água, e crêem que dançam, e que as danças se prolongam até à madrugada. São casos puramente patológicos. Não há neles a menor sombra de comissão, ao menos no estado agudo da moléstia, porque é observação feita que, quando a cura começa a operar-se, o doente ilude-se a si mesmo, arranjando uma comissão de verdade, que vai deveras à casa dele com a venera, que ele mesmo comprou, e lhe fazem discursos, comem realmente, e as danças prolongam-se até de manhã... ${ }^{36}$

\footnotetext{
${ }^{33}$ CASTELO. Proust no casulo apud PIMENTEL; TURAZZI. Ensino de história: diálogos com a literatura e a fotografia, p. 169.

${ }^{34}$ PROUST. O tempo redescoberto apud BRASSAÏ. Proust e a fotografia, p. 13.

${ }^{35}$ VAINFAS. Dicionário do Brasil imperial (1822-1889), p. 504.

${ }^{36}$ ASSIS. Balas de Estalo, p. 2.
} 
Quando o editor Lombarts faleceu, em 1897, foi Machado quem lhe escreveu o obituário nas páginas d'A Estação. Retrato póstumo e emotivo, que parecia revelar não somente as qualidades do editor e amigo, mas aquelas que o antigo colaborador tomava também para si:

Durante muitos anos entretive com Henrique Lombaerts as mais amistosas relações. Era um homem bom, e bastava isso para fazer sentir a perda dele; mas era também um chefe cabal da casa herdada de seu pai e continuada por ele com tanto zelo e esforço. Posto que enfermo, nunca deixou de ser o mesmo homem de trabalho. Tinha amor ao estabelecimento que achou fundado, fez prosperar e transmitiu ao seu digno amigo e parente, atual chefe.

A Estação e outras publicações acharam nele editor esclarecido e pontual. Era desinteressado, em prejuízo dos negócios a cuja frente esteve até o último dia útil da sua atividade. Não é demais dizer que foi um exemplo a vida deste homem, um exemplo especial, por que no esforço continuado e eficaz, ao trabalho de todos os dias e de todas as horas não juntou o ruído exterior. Relativamente expirou obscuro; o tempo que lhe sobrava da direção da casa era dado à esposa, e, quando perdeu a esposa, às suas recordações de viúvo. ${ }^{37}$

A imagem de si, um dos elementos essenciais da autoconsciência, é fonte de inspiração, mas também de desassossego. Em tudo que já se disse sobre Machado, especula-se muito sobre sua visão de si mesmo, particularmente aquela que pode ser colhida nas obras literárias que escreveu. Lucia Miguel Pereira defendia que o conselheiro Aguiar (Memorial de Aires) era o personagem que mais se aproximaria de um autorretrato. Outros, viram em certo poema, a expressão de sua "alma interior" em versos:

\section{Uma Criatura}

Sei de uma criatura antiga e formidável,

Que a si mesma devora os membros e as entranhas,

Com a sofreguidão da fome insaciável.

Habita juntamente os vales e as montanhas;

E no mar, que se rasga, à maneira de abismo,

Espreguiça-se toda em convulsões estranhas.

Traz impresso na fronte o obscuro despotismo.

Cada olhar que despede, acerbo e mavioso,

Parece uma expansão de amor e de egoísmo.

Friamente contempla o desespero e o gozo,

Gosta do colibri, como gosta do verme,

E cinge ao coração o belo e o monstruoso.

Para ela o chacal é, como a rola, inerme;

E caminha na terra imperturbável, como

Pelo vasto areal um vasto paquiderme.

${ }^{37}$ ASSIS. A Estação, 15 jul. 1897, p. 78. 
$\mathrm{Na}$ árvore que rebenta o seu primeiro gomo Vem a folha, que lento e lento se desdobra, Depois a flor, depois o suspirado pomo.

Pois essa criatura está em toda a obra: Cresta o seio da flor e corrompe-lhe o fruto; E é nesse destruir que as forças dobra.

Ama de igual amor o poluto e o impoluto;

Começa e recomeça uma perpétua lida,

E sorrindo obedece ao divino estatuto.

Tu dirás que é a Morte; eu direi que é a vida. ${ }^{38}$

Os retratos de Machado refletidos no "espelho com memória" parecem ter ajudado essa imensurável "criatura humana" a conhecer um pouco mais de si mesmo e, nele, as duas "almas" que trazia consigo. Por isso mesmo, eles também nos ajudam, como sugeriu Proust, "a ler de certa forma", para ler melhor, a obra e a alma machadiana.

\section{A B S TRACT}

This article presents and discusses a set of information, some of them still unpublished, about a portrait of Machado de Assis (1839-1908) taken by the photographer Marc Ferrez (18431923). Analyzing this image as well as its context of production and circulation (1880-1884), we sought to identify and amplify relevant questions for the study of the relationship between literature and photography. We believe that history of photography in general, and the history of this particular portrait, when articulated to the Brazilian editorial scenario in nineteenth century and the immense critical fortune on Machado de Assis' life and work, can brighten obscure aspects of his biography and, at the same time, launch new questions and interpretations on the writer's imagination.

\section{KEYWORDS}

Photography, literature, Machado de Assis, Marc Ferrez, portrait

${ }^{38} \mathrm{O}$ poema foi incluído no último livro de poesias de Machado, lançado como volume de poesia completa em 1901. 


\section{REFERÊNCIAS}

A ESTAÇÃO: JORNAL ILLUSTRADO PARA A FAMILIA. Rio de Janeiro, ano XX, n. 9, 15 maio 1891. Disponível em: < http://memoria.bn.br/DocReader/DocReader.aspx? $\mathrm{bib}=709816 \&$ PagFis $=3552>$. Acesso em: $5 \mathrm{dez} .2014$.

A ESTAÇÃO: JORNAL ILLUSTRADO PARA A FAMILIA. Rio de Janeiro, ano XX, n. 18, 30 set. 1891. Disponível em: <http://memoria.bn.br/DocReader/DocReader.aspx? bib $=709816 \&$ PagFis $=3552>$. Acesso em: 5 dez. 2014.

A ESTAÇÃO: JORNAL ILLUSTRADO PARA A FAMILIA. Rio de Janeiro, ano XXVI, n. 13, 15 jul. 1897. Disponível em: < http://memoria.bn.br/DocReader/DocReader.aspx? bib $=709816 \&$ PagFis = 5601>. Acesso em: 5 dez. 2014.

ASSIS, Machado de. Ao acaso. Diário do Rio de Janeiro, Rio de Janeiro, ano XLIV, n. 217, 7 ago. 1864. p. 1.

ASSIS, Machado de. Balas de Estalo. Gazeta de Notícias, Rio de Janeiro, ano X, n. 136, 15 maio 1884. Balas de Estalo, p. 2. Disponível em: < http://memoria.bn.br/DocReader/ docreader.aspx?bib=103730_02\&PagFis=5127>. Acesso em: 5 dez. 2014.

ASSIS, Machado de. Correspondência de Machado de Assis. Coordenação e orientação de Sergio Paulo Rouanet; reunida, organizada e comentada por Irene Moutinho e Sílvia Eleutério. Rio de Janeiro: Academia Brasileira de Letras, 2008-2011. 3 v.

ASSIS, Machado de. Livros a Ler. Revista Illustrada, Rio de Janeiro, ano 9, n. 389, 31 ago. 1884. Livros a Ler, p. 6.

ASSIS, Machado de. O espelho. In: Papéis avulsos. Rio de Janeiro: Livraria Lombaerts \& Cia, 1882. Disponível em: <http://www.literaturabrasileira.ufsc.br/ documentos $/$ ?action $=$ download\&id $=31110>$. Acesso em: 5 dez. 2014.

ASSIS, Machado de. Obra completa. Rio de Janeiro: Nova Aguilar, 2008. 4 v.

ASSIS, Machado de. Poesias completas (Crisálidas, Falenas, Americanas, Ocidentais). Rio de Janeiro: H. Garnier, 1901. Disponível em: <http://www.machadodeassis.ufsc.br/ obras/poesias/POESIA,\%20Ocidentais,\%201901.htm\#UMACRIATURA>. Acesso em: 5 dez. 2014.

BARREIROS, Arthur. Biografia de Machado de Assis. Rio de Janeiro: Lombaerts e Cia, 1884 apud PIZA, Daniel. Machado de Assis, um gênio brasileiro. 2. ed. São Paulo: Imprensa Oficial, 2006. p. 237-238.

BAUDELAIRE, Charles. Salon de 1859 apud FABRIS, Annateresa. Identidades virtuais: uma leitura do retrato fotográfico. Belo Horizonte: Editora UFMG, 2004. p. 21.

BOSI, Alfredo. Machado de Assis: o enigma do olhar. São Paulo: Ática, 1999.

BRASSAÏ, Howard. Proust e a fotografia. Rio de Janeiro: Zahar, 2005.

CASTELO, José. Proust no casulo. O Globo, 10 mar. 2012 apud PIMENTEL, Júlio; TURAZZI, Maria Inez. Ensino de história: diálogos com a literatura e a fotografia. São Paulo: Moderna, 2013. p. 169. [Obra selecionada pelo Programa Nacional de Biblioteca na Escola].

CIORAN, Emile M. Antologia do retrato: de Saint-Simon a Tocqueville. Rio de Janeiro: Rocco, 1998. 
COELHO, Marcelo. Memorial do mestre. In: INSTITUTO MOREIRA SALLES. Cadernos de Literatura Brasileira: Machado de Assis. São Paulo, 2007. Confluências, p. 49-51.

COURTINE, Jean-Jacques; CLAUDINE, Haroche. História do rosto. Lisboa: Teorema, 1995. ENCICLOPÉDiA ITAÚ CULTURAL. Insley Pacheco. Disponível em: <http:// enciclopedia.itaucultural.org.br/pessoa21635/Insley-Pacheco >. Acesso em: 5 dez. 2014. ERMAKOFF, George. Dicionário biográfico ilustrado de personalidades da história do Brasil. Rio de Janeiro: George Ermakoff Casa Editorial, 2012.

ERMAKOFF, George. Rio de Janeiro, 1840-1900: uma crônica fotográfica. Rio de Janeiro: George Ermakoff Casa Editorial, 2006.

FABRIS, Annateresa. Identidades virtuais: uma leitura do retrato fotográfico. Belo Horizonte: Editora UFMG, 2004.

FERREIRA, Orlando da Costa. Imagem e letra: introdução à bibliologia brasileira: a imagem gravada. São Paulo: Melhoramentos / Edusp, 1977.

GRANDES PERSONAGENS (MACHADO DE ASSIS). São Paulo: Abril Cultural, 1969. v. 6, p. 25-40.

GUIMARÃES, Hélio de Seixas; SACCHETTA, Vladimir. A olhos vistos: uma iconografia de Machado de Assis. São Paulo: Instituto Moreira Salles, 2008.

INSTITUTO MOREIRA SALLES. Cadernos de Literatura Brasileira: Machado de Assis. São Paulo, 2007.

KEN, Alexandre. Dissertations historiques, artistiques et scientifiques sur la photographie. Paris: Librairie Nouvelle, 1864.

MACHADO, Ubiratan. Dicionário de Machado de Assis. Rio de Janeiro: Academia Brasileira de Letras, 2008.

MAUAD, Ana Maria. Poses e flagrantes: ensaios sobre história e fotografias. Niterói: EdUFF, 2008.

PEREIRA, Lucia Miguel. Machado de Assis: estudo crítico e biográfico. São Paulo: Nacional, 1936.

PIMENTEL, Júlio; TURAZZI, Maria Inez. Ensino de história: diálogos com a literatura e a fotografia. São Paulo: Moderna, 2013. [Obra selecionada pelo Programa Nacional de Biblioteca na Escola].

PIZA, Daniel. Machado de Assis, um gênio brasileiro. 2. ed. São Paulo: Imprensa Oficial, 2006.

PROUST, Marcel. O tempo redescoberto apud BRASSAÏ, Howard. Proust e a fotografia. Rio de Janeiro: Zahar, 2005. p. 13.

STRÄTER, Thomas. De retratos, espelhos e reproduções: o olhar fotográfico de Machado de Assis. In: NUNES, Benedito; MOTTA, Sérgio Vicente (Org.). Machado de Assis e a crítica internacional. São Paulo: Editora UNESP, 2009. p. 91-128.

TAXIL, Jean. L'astrologieet la physiognomonie en leursplendeur, 1614 apud COURTINE, Jean-Jacques; CLAUDINE, Haroche. História do rosto. Lisboa: Teorema, 1995. p. 45.TURAZZI, Maria Inez. A máquina viajante. Revista de História da Biblioteca Nacional, Rio de Janeiro, n. 52, p. 18-25, jan. 2010. 
TURAZZI, Maria Inez. A vontade panorâmica. In: FERREZ, Marc. O Brasil de Marc Ferrez. São Paulo: Instituto Moreira Salles, 2005.

TURAZZI, Maria Inez. Cronologia. In: FERREZ, Marc. O Brasil de Marc Ferrez. São Paulo: Instituto Moreira Salles, 2005.

VAINFAS, Ronaldo (Dir.). Dicionário do Brasil imperial (1822-1889). Rio de Janeiro: Objetiva, 2002.

\section{SITES}

Academia Brasileira de Letras. Apresenta informações sobre a ABL. Disponível em: $<$ http://www.academia.org.br $>$. Acesso em: 5 dez. 2014.>

Hemeroteca Digital Brasileira. Disponibiliza consulta ao acervo de periódicos e de publicações seriadas da Fundação Biblioteca Nacional. Disponível em: < http:// hemerotecadigital.bn.br >. Acesso em: 5 dez. 2014.

Instituto de Letras e Artes - Eco do Sul. Apresenta informações sobre a produção literária no jornal Eco do Sul. Disponível em: <http://www.ecodosul.furg.br >. Acesso em: 5 dez. 2014.

Machado de Assis. Apresenta informações sobre o acervo do autor reunidas pela Academia Brasileira de Letras. Disponível em: <http://www.machadodeassis.org.br $>$. Acesso em: 5 dez. 2014.

Portal Domínio Público. Disponibiliza obras literárias, artísticas e científicas em domínio público. Disponível em: < http://www.dominiopublico.gov.br>. Acesso em: 5 dez. 2014.

Recebido em 1 de julho de 2014 Aprovado em 26 de dezembro de 2014 